\title{
Creative practice with clay: A mutual route to recovery?
}

\author{
Elaine Argyle, University of Nottingham \\ Gary Winship, University of Nottingham
}

\begin{abstract}
This article summarises the findings of a project called 'Clay Transformations' and was part of the Creative Practice as Mutual Recovery Programme funded by the Arts and Humanities Research Council. Using a mixed methods approach, the project aimed to assess the extent to which involvement in clay workshops promoted the well-being of a group of 42 participants, including mental health service users, artists and practitioners. A particular focus in this respect was placed on the incidence of 'mutual recovery' which extends the concept of recovery beyond the individual to incorporate the wider group and its context. It was subsequently found that workshop involvement helped to promote, not only the well-being and mutual recovery of participants, it also enhanced the supportive capacities and social capital of the settings in which these activities took place, both within the workshops and beyond.
\end{abstract}

Keywords: arts participation, psychological and social well-being, creativity, mutual recovery, social inclusion, clay work

\section{INTRODUCTION}

The increasing popularity of the role of the arts in promoting well-being of participants is reflected in the proliferation of literature on the subject (Crawford et al. 2013, 2015; Goulding 2014). This beneficial aspect of arts involvement has been upheld by much research, especially in the field of mental health recovery which has demonstrated the importance of creative practice in enabling participants to live more meaningful and resilient lives (Crawford et al. 2013). However, within this growing body of research, an individualised approach has tended to be adopted. For although traditional recovery models adopt a holistic approach to mental health, focusing on the person as well as their symptoms, this person-centred focus tends to neglect the context in which this recovery is located (Crawford et al. 2015). Within creative practice interventions, this context could relate both to the group in which this activity takes place as well as to the wider community and its resources. For example, in a recent review Van Lith et al. (2013) found that research 
on the impact of art-based practice on mental health recovery was dominated by a psychological approach with a subsequent focus on individual well-being with little reference to the wider environment. Even when social themes were identified, these were of a largely individualised focus including such things as the development of social skills, wellbeing and identity and the respective attributes of workshop facilitators. In order to broaden this focus, the concept of recovery has been recently extended beyond an individualised approach to the more inclusive one of 'mutual recovery'. This incorporates the therapeutic role of groups and communities (Winship 2016) and the experiences of diverse groups, thus integrating strategies and understandings that have previously been separated.

In order to further establish and explore this concept of mutual recovery, its precise components need to be explored and effective strategies for its implementation need to be developed. Engagement in creative practices, including clay work, which have long been used in recovery orientated mental health services, may provide such strategies. For these practices have the potential, especially when shared, to transcend divides between groups and communities, enhance the incidence of reciprocal exchange and promote the coproduction of creative capital and resources all of which are beneficial to individual wellbeing (Crawford et al. 2013). In recognition of these issues, the Creative Practice as Mutual Recovery Programme, which was funded by the Arts and Humanities Research Council (AHRC), was launched. The main impetus behind this programme has been the belief that research into the therapeutic use of creative interventions have, to date, not assessed the needs of adults with mental health problems, carers and professionals in tandem, leading to fragmented and divided community activities. Incorporating a number of separate projects, it has investigated the way in which creative practice in the arts and humanities can enhance mental health and well-being, establish and connect communities and promote mutual recovery. The project reported on here forms part of this wider programme and aims to explore and elaborate the above issues and ideas and their relationship to creative practice with clay.

As a starting point for this project, which is called 'Clay Transformations', a literature review was carried out on the therapeutic use of clay. Relevant articles were identified from countries such as the United States (Henley 2002), Canada (White 2006), Australia (Sherwood 2004), Japan (Kameguchi and Murphy-Shigematsu 2001) and India (NIMHANS 2007). Themes emerging from this literature are summarised below. 


\section{The process of clay work}

Clay is a resistant but malleable material which allows the participant to dig, bang, bend and shape their work (Winship and Haigh 1998). This work is regarded as being both tactile and kinaesthetic involving the sense of touch and physical interaction which has been found to be innately therapeutic but which can also provoke negative responses due to its potential messiness (Henley 1991). Clay work is also seen as having regressive qualities in that it is widely used by and accessible to children (White 2006) and can link adults to their childhood experiences (Elkis-Abuhoff et al. 2008). Moreover, clay is a relatively affordable art material and working with it is often seen as less intimidating and requiring less skill and expense than other forms of creative practice (Argyle and Winship 2015). The sense of achievement, increasing confidence and self-esteem that can result from this work can also be beneficial (White 2006).

\section{The outcome of clay work}

Increases in self-esteem and confidence are not only confined to the process of clay work but also to the outcome, with clients working with clay reporting benefits as a result of creating something that they can be proud of (Argyle and Winship 2015). However, drawing on psychoanalytical approaches, the outcome benefits of clay work relate, most commonly, to discussions around the representative nature of what is created. Thus it is seen to create a three-dimensional and tangible expression of thoughts and emotions which can be central to the therapeutic process (Sholt et al. 2006; Winship and Haigh 1998). This is particularly apparent in the therapeutic use of clay effigies which can often represent traumatic events from the past (Anderson 1995). Similarly, the work of Sherwood (2004) aimed to empower participants by asking them to make clay models of 'ideal parents'. The nature of clay lends itself particularly well to this use of symbolism (Waller 1993) and the expression of both the individual and collective unconscious (Jung 1995). This expressive feature is facilitated by the tactile quality of clay work which enhances participants' ability to engage with their emotions (Anderson 1995) and their subsequent exploration through the use of verbal therapy.

\section{The context of clay work}

In spite of the prominence of issues of process and outcome in literature on the therapeutic use of clay, the context in which this work takes place can also play a therapeutic role. Henley (2002) found that working with clay enabled the exploration of communal conflicts 
and cultural issues. In addition, clay work taking place in a group can promote mutual interaction and learning, facilitate the group's supportive capacities and establish sustained social contacts as a result of shared experiences (Argyle and Winship 2015). Such processes have themselves been found to have a significant impact on the social and psychological well-being of individual members (Argyle and Bolton 2004). Thus, the incidence of mutuality and reciprocity within group and community settings can help to accelerate the process of mental health recovery (Pernice-Duca 2010). In recognition of these group and community processes, and their potentially reciprocal nature, recent years have seen the growth of Arts for Health programmes. These involve partnerships between artists and institutions with the aim of promoting community integration and development through such things as the public display of completed work (Argyle and Bolton 2005). However, such broad impacts have been generally overlooked in research into the therapeutic aspects of clay work which has been traditionally dominated by psychotherapeutic approaches and Freudian analysis (Sholt et al. 2006).

\section{METHODOLOGY}

\section{Aims}

The concept of mutual recovery provides a socially-inclusive approach to mental health recovery that integrates some strategies and understandings that have been separated in the past. The new integration suggested by mutual recovery needs fresh strategies for implementation. Creative arts practices, clay work in particular, may provide such strategies. This article reports a study that aims to establish if and how creative practice with clay can promote the well-being and mutual recovery of participants.

\section{Procedure}

Three blocks of eight-week clay workshops were run in the Clay Transformations project. A diverse group of 42 volunteer participants took part, attending one block each. Weekly workshops lasted for around three hours and were run by a local community arts provider. They were facilitated by two separate artists with one taking the first four weeks and the other taking the last four weeks of each block. The artists adopted very different approaches to the sessions. The first used an unstructured approach with a focus on clay sculpting and mask making and with completed work being photographed, then destroyed. The second was a more traditional 'potter' whose sessions tended to be more formal and follow step by step instructions on specific tasks such as the making of tiles and pots which were 
subsequently glazed and fired. All 24 workshops were attended by the project researcher whose role was to evaluate the sessions and their impact upon participant's well-being (Argyle 2015).

In order to capture the complexity of the issues being addressed, a mixed methods approach was adopted in this evaluation. This included the administration of two wellbeing questionnaires completed by participants at the first, middle and last session of each block of workshops. Only those that responded at all three-time points were included in the statistical analysis of questionnaire responses. In order to 'look behind' these statistics and find out 'how' as well as 'whether' well-being was impacted by attendance at the clay sessions, qualitative methods were also utilised. Such methods also had the advantage of incorporating user perspectives which are central to concepts of mutual recovery and the corresponding discipline of health humanities (Crawford et al. 2015). Qualitative data collection took an iterative approach and was conducted on an ongoing basis. Ethical principles including informed consent and confidentiality were adhered to throughout this process.

\section{Materials}

Questionnaires used were the short Secker Social Inclusion Measure (Secker et al. 2009) and the long Warwick-Edinburgh Mental Well-being Scale (WEMWBS) (Tennant et al. 2007). These are popular measures (Saavedra et al. 2018) and in order to facilitate comparison, they were used across all projects on the wider Creative Practice as Mutual Recovery Programme. They helped to address the primary research aim by determining whether clay work had an impact on the social and psychological well-being of participants. Data were analysed using SPSS 22.0. Measures were then subject to parametric testing using repeated measures and analysis of variance (ANOVA) to identify any significant differences in scores between measurements. Qualitative methods included participant observation, reflective logs, 1-1 interviews with all participants during week one and week eight of each block and a focus group in the final session. Focus groups and interviews were audio recorded, transcribed, coded and analysed utilising the principles of grounded theory with emergent themes being identified and pursued (Bryman 2012).

\section{Participants}

Of the 42 people registered for the workshops, all but four were white and British. The majority (34) attended at least five of the eight sessions and 29 people completed the full 
set of baseline, mid-term and final well-being questionnaires - 13 did not (block 1- 4; block 2- 3; block 3-6). As it can be seen in table 1, participants came from diverse backgrounds and included mental health service users (MHSUs), artists and practitioners. However, the distinction between their respective identities was often blurred, with seven of those taking part combining multiple roles such as artist and practitioner or artist and mental health service user. Indeed, for many participants there was a close relationship between art involvement and mental health with some having become artists as a means of dealing with mental health issues. Others were accomplished artists due to their involvement in creative practice as mental health service users. With regard to participants' motives for attending the workshops, common themes included the wish to relax, meet people and learn new skills, especially amongst mental health service users. Motives expressed specifically by most of the artists and practitioners included the wish to experience a therapeutic intervention from a participant's perspective and in an unpressurised and non-judgemental environment.

\begin{tabular}{|l|l|l|l|l|l|l|l|l|l|}
\hline Group & \multirow{2}{*}{ No. } & \multicolumn{2}{l}{ Gender } & \multicolumn{2}{l|}{ Age group } & \multicolumn{2}{l|}{ Participant role } \\
\cline { 3 - 10 } & & female & male & $18-40$ & $41+$ & MHSU & artist & practitioner & mixed \\
\hline 1 & 14 & 13 & 1 & 2 & 12 & 8 & 1 & 1 & 4 \\
\hline 2 & 11 & 9 & 2 & 2 & 9 & 3 & 3 & 3 & 2 \\
\hline 3 & 17 & 12 & 5 & 6 & 11 & 12 & 4 & 0 & 1 \\
\hline Total & 42 & 34 & 8 & 10 & 32 & 23 & 8 & 4 & 7 \\
\hline
\end{tabular}

Table 1: Participant profile

\section{FINDINGS}

\section{Well-being questionnaires}

As it can be seen from table 2, for the 29 participants who completed baseline, midterm and final well-being questionnaires, scores significantly improved for both social inclusion and mental well-being over the course of the workshops. This improvement was apparent in mental well-being scores from baseline (43.41) to midterm (47.90) to final (51.78); and social inclusion scores from baseline (35.28) and midterm (36.52) to final (39.17). The subconstructs of the social inclusion scale (social isolation, social relations and social acceptance) followed the same pattern as social inclusion overall, apart from social acceptance which only improved from baseline to final but not from midterm to final. There were no significant 
differences in scores between participants of different age groups $(<40 ; 40-49 ; 50-59 ;>59)$ or the blocks in which participants took part (1,2 or 3). The only notable differences observed between groups of participants were for those of different identities at baseline measurement. Thus, mental health service users had significantly lower scores for social inclusion (32.86) and for mental well-being (43.20) compared to other participants at baseline. However, these differences resolved at midterm and at final measurement points whereby no significant differences were observed between different groups of participant identities for either social inclusion or mental well-being.

\begin{tabular}{|l|l|l|l|l|l|l|l|}
\hline \multirow{2}{*}{ Group } & \multirow{2}{*}{ No. } & \multicolumn{3}{|l|}{ Social Inclusion (Secker) } & \multicolumn{3}{l|}{ Mental Well-being (WEMWBS) } \\
\cline { 3 - 7 } & & Baseline & Midterm & Final & Baseline & Midterm & Final \\
\hline 1 & 10 & 34.80 & 36.80 & 40.80 & 43.60 & 48.00 & 53.20 \\
& & $(7.07)$ & $(7.19)$ & $(6.09)$ & $(12.10)$ & $(10.32)$ & $(8.99)$ \\
\hline 2 & 8 & 36.00 & 36.75 & 38.75 & 43.88 & 46.00 & 51.25 \\
& & $(7.09)$ & $(6.34)$ & $(5.90)$ & $(10.25)$ & $(9.49)$ & $(11.25)$ \\
\hline 3 & 11 & 35.18 & 36.09 & 38.00 & 42.91 & 49.18 & 50.86 \\
& & $(5.81)$ & $(4.50)$ & $(4.88)$ & $(8.55)$ & $(8.07)$ & $(10.88)$ \\
\hline Overall & 29 & 35.28 & 36.52 & 39.17 & 43.41 & 47.90 & 51.78 \\
& & $(6.40)$ & $(5.83)$ & $(55.4)$ & $(9.98)$ & $(9.04)$ & $(10.05)$ \\
\hline
\end{tabular}

Table 2: Means (and standard deviations) of social inclusion and mental well-being scores at baseline (week 1), midterm (week 4) and final (week 8) measurements for each block of participants and overall.

\section{Post workshop reflections}

The positive outcomes shown by statistical measures were reflected in the qualitative data as, although the sessions lacked a verbal psychotherapeutic content, they were nevertheless experienced as being beneficial. Five interrelated themes were identified from participants' qualitative accounts of the sessions as contributing to this positive experience.

\section{Group membership}

The role of creative practice in promoting interaction and the supportive capacities of the group more generally were seen as having a positive impact on mental well-being. Thus, participants spoke of the benefits deriving from group membership and the sense of 
acceptance, belonging and mutual support that can arise from this, 'Throughout the sessions we have developed help and support from and for each other, not only with regard to the work but also in other in other aspects of our lives and some particular bonds have developed' (Female, MHSU, group 3).

For this respondent, the level of intimacy that had developed which was 'rather unusual in such a newly formed group' with the atmosphere being consistently 'positive, comfortable and supportive'. The sessions also provided participants, many of whom were unemployed, with a structure to their week and combated social isolation: 'So coming out and actually being with people, making a commitment to come out every Monday is a huge thing' (Male, MHSU, group 3). These aspects of mutuality, reciprocity and group cohesion were enhanced by the fact that participants were having a shared experience: 'I've noticed that because were having a shared experience and working on the same tasks, that does kind of help in getting to know people' (Female, practitioner, group 1). The diversity of group participants facilitated these processes, serving to minimise the hierarchal divisions often apparent in more traditional therapeutic sessions: 'I think it's good for all our mental health to have that mix rather than a hierarchy. I think it addresses the power thing that can be an issue' (Female, artist, group 2).

\section{The medium of clay}

A significant perceived benefit from workshop attendance was the unique experience of working with clay, its accessibility and flexibility as well as its tactile and regressive qualities:

What I really like about the clay is that it's really tactile. If you don't like what you've done you can just kind of start again. It's not permanent. It's fun as well, it's a bit like being back at school. (Female, practitioner, group 2)

In this respect it should be recognised that participants were a self-selecting group who actively wanted to work with clay and apart from some creative frustrations, few expressed negative reactions to the material itself. Nevertheless, their reactions to clay work was significantly influenced by the contrasting approaches of the project artists. Some participants, particularly mental health service users, preferred the traditionally instructed pottery sessions which allowed them to acquire basic skills as well as to keep the final products of their work rather than have them photographed and destroyed: 'It seemed a shame that what we were spending all that time and effort on was not going to be kept' (Female, 
MHSU, group 1). Others preferred the more unstructured facilitated sessions in clay sculpting as it appeared to promote confidence and cohesion within the group. Artists also felt that this more unconventional approach relieved them from the pressure of creative expectation experienced in their working life enabling them to access their personal responses to the material. As one participant said of the artist running the clay sculpting sessions: 'His encouragement to examine and engage with one's thoughts and feelings demonstrated how those responses can both inform and find expression in the work' (Female, artist, group 2).

\section{The process of creative practice}

Another theme emerging was the process of involvement in art creation which allowed participants to relax: 'Conversations held in twos and threes, held side by side rather than face to face, were often quite revealing, as if the manual focus on the clay freed the cares of the mind' (Female, MHSU, group 3). As such, most participants thought that this process of clay work was of equal or greater importance than the outcome for it promoted a sense of creative freedom. The focus on process also helped to bypass psychotherapeutically orientated interpretations of their work which were often perceived to be unhelpful: 'I think it stops your natural creative process if you think about what it means' (Female, MHSU, group 1). This sense of creative freedom was particularly apparent for the practitioners and artists who also alluded to the way in which workshop participation helped them to resolve their multiple identities. For example, an artist and psychotherapist in group 1 wanted to experience working with clay from both the points of view of a client and as an artist. She also experienced unanticipated benefits from her attendance in terms of stress release and the absence of professional expectations: 'It's just felt like the type of space that I used to have as a child when I could just enjoy an art class so when I come here I start to go into a stress-free zone' (Female, mixed roles, group 1).

\section{The outcome of creative practice}

In spite of this focus on process, the outcome of this work was also seen as important due to its symbolic qualities. This symbolism potentially took place on three different levels. Firstly, although the workshops did not incorporate a psychotherapeutic content, for some participants, their work represented something about themselves. For example, a mental health service user suggested some psychoanalytical insights into her completed work: 
It had suddenly become something quite personal that represented me. And it didn't have a mouth because I felt I didn't have a voice, particularly with reference to my depression and what treatment and help I get (or don't get, more to the point!). (Female MHSU, group 3)

A second symbolic quality of the completed work was that it reminded participants of the experience of the clay workshops and the other people taking part: 'It's not that I have made anything of merit or any use, it is just that it has memories attached to it' (Female, MHSU, group 3). Thirdly, the completed work was seen to represent the skills gained and demonstrated by participants which could, in itself, have a therapeutic effect. As such, participants, regardless of their background, successfully produced an impressive range of work which gave rise to a sense of achievement and pride, enhancing their creative confidence and esteem. As a mental health service user said: 'I had never thought of myself as being creative in any manual sense. Being able to say that I liked how a finished piece looked was an unexpected delight' (Female, MHSU, group 3). In contrast to the benefits of process, these outcome benefits also had the advantage of transcending the transient workshop experience and having a sustained and lasting impact.

\section{$A$ wide ranging and lasting impact}

A truly therapeutic experience should be one that goes beyond the sessions themselves and within this project this goal was achieved in a number of ways. Thus, at the end of each set of workshops, attendance certificates were given out and the manager of the workshop venue gave a signposting talk to participants, indicating ways in which they could further pursue their artwork. Some participants went on to enrol on courses in ceramics or clay sculpture and others used the sessions as a networking opportunity helping them to meet other likeminded people and seek out relevant opportunities. For example, two artists in the second group were planning on setting up their own clay workshops while several of the other artists and practitioners felt that they had acquired skills that could be used in their working lives.

The workshop venue also went on to run more clay sessions after the project had finished, due to the amount of interest expressed and the two workshop facilitators also obtained further work as a result of their involvement in the project. For example, the clay sculpting specialist was invited to run a clay workshop for clients and volunteers at a local dementia day centre and was subsequently rebooked to run regular sessions. It was the first time this group had worked with clay and the session was described by the group leader as: 
'One of the most successful we have had in nearly two years and totally different from the rest'. In addition, three public exhibitions of completed work were held which were very well received, thus as one attendee described it: 'inspiring and grounding at the same time'. After the exhibitions, a reunion took place for participants when they were able to collect their completed work. Uncollected work was then sold at a charity fundraising event held at the host research institution with many offices in this institution now displaying this work as a lasting reminder of the Clay Transformations project. These broad and sustained impacts show how the intervention promoted not only the well-being of individual participants but also the supportive capacities and social capital of the community in which it was located. This wider impact was a two-way process and not always positive, with some participants referring in negative terms to the general impact of 'government cuts' on mental health care provision and the marginality of creative practices within this provision meaning that: 'Care is generally not adequate now for those who need it most' (Female, MHSU, group 3).

\section{DISCUSSION}

The statistical findings of this research (table 2) have shown that the psychological well-being of participants (Tennant et al. 2007) significantly improved on all measures throughout all three blocks of workshops. The results for the multi-dimensional social inclusion measure (Secker et al. 2009) were also positive but slightly more complex and in need of further exploration in subsequent studies. These generally positive findings were reflected in the qualitative data collected which echo many of the benefits of art involvement found in similar studies (Sholt et al. 2006). These expressed benefits included aspects of process, outcome and the unique features of clay work. In accordance with concepts of mutual recovery, these benefits appeared to be facilitated by the fact that the work was taking place in a group context with its supportive aspects being enhanced by the apparent lack of hierarchical divisions.

This lack of hierarchy was further promoted by the diverse roles of group members (table 1) which also encouraged a relatively broad-based level of engagement and assisted in the inclusion of 'hard to reach' groups. However, in spite of this role diversity, men, people aged 40 and under and ethnic minorities were all significantly under-represented amongst workshop attendees. Role diversity also gave rise to conflicting perspectives on the approaches to workshop facilitation adopted by the two project artists with many mental health service users preferring formal sessions, while participating artists favoured a more unstructured approach. This further highlights the importance of the group context on the 
experiences of participants. It also raises questions on how these conflicting preferences can best be recognised, reconciled and responded to when running such sessions with diverse groups. Further questions include the relative impact of being in a group on one hand and of engagement in creative practice on the other, the respective benefits of different types of creative activity on the process of mutual recovery as well as the best way of measuring this.

Consequently, while the efficacy of creative practice interventions must be proven if appropriate funding for them is to be obtained and maintained, there are significant methodological problems in measuring this efficacy (Van Lith et al. 2013). This is due, for example, to the difficulty in standardising intervention design and delivery and their sensitivity to features of the local, national and group context (Bryman 2012; Goulding 2014). These problems are compounded when attempting to measure any mutual recovery resulting from these interventions. For although the mixed methods approach adopted in this project is widely advocated as being the most appropriate way of gaining a comprehensive understanding in this area (Van Lith et al. 2013), the well-being scales used in this research may have been less appropriate. For they tend to adopt an individualised focus which is not fully compatible with the broader and more social approach that the concept of mutual recovery advocates. Moreover, the positive results yielded from these well-being scales were not a true reflection of the experience of all 42 participants, in that it included only those 29 participants who were present when the questionnaires were distributed. The experiences of the 13 participants who did not attend many sessions were therefore excluded and may have been less positive.

A further limitation of this project is that, like many other creative practice interventions, it was characterised by short term funding. This issue was implicitly referred to by some participants who complained about the lack of long term availability of the sessions as well as about wider service cutbacks more generally (Dorling 2013). As a result of this, the scope and sustainability of the project impact was compromised. The possibility of evaluating its impact in the longer term was also undermined, which Van Lith et al. (2013) recognise to be an important but neglected goal for creative practice interventions. In spite of these limitations, measures were taken to extend the impact of this project after the workshops had ended. These included such things as post intervention guidance on accessing other art activities, reunions, exhibitions and charity fundraising events as well as the continued creative practices of participants and workshop facilitators. Following completion of this research, social media have also been utilised through the continued maintenance of a project Facebook page and through a project video which is shown at relevant meetings and 
exhibitions. Consequently, like relationships between participants, the relationship between the intervention and its wider context has been a reciprocal one (Pernice-Duka 2010; Walker 2014). For, in a context in which supportive provision is increasingly scarce and fragmented (Argyle and Winship 2015), this project has helped to promote the incidence of cooperation and mutual support between diverse groups within the workshop settings and beyond.

\section{CONCLUSIONS}

As part of the Creative Practice as Mutual Recovery programme, the study presented here has demonstrated the significance of arts involvement in the process of mental health recovery. In focussing on the mutual aspects of this recovery, it has avoided the individualised and psychotherapeutically orientated approaches which have traditionally dominated research into the therapeutic use of clay. While, in contrast to traditional models of recovery, it has evaluated the experiences of diverse groups simultaneously. In adopting this focus, it has highlighted the benefits of clay work deriving not only from the process and outcome of this work but also from the wider contexts in which this work takes place. These impacts were broad, sustained and mutually reinforcing, transcending the individual and the group to incorporate wider settings. This in turn suggests the need for traditional concepts of recovery to broaden their person-centred focus to incorporate the wider contexts and processes described in this study, which can facilitate the incidence of mutual recovery.

\section{REFERENCES}

Anderson, F. (1995), 'Catharsis and empowerment through group clay-work with incest survivors', The Arts in Psychotherapy, 22:5, pp. 413-27.

Argyle, E. (2015), ‘A potter's day’, Ceramic Review, 272, p. 79.

Argyle, E. \& Bolton, G. (2004), 'The use of art within a groupwork setting', Groupwork, 14:1, pp. 46-62.

Argyle, E. \& Bolton, G. (2005), 'Art in the community for potentially vulnerable mental health groups', Health Education, 105:5, pp. 340-54.

Argyle, E. and Winship, G. (2015), 'Creative practice in a group setting', Mental Health and Social Inclusion, 19:3, pp. 141-47.

Bryman, A. (2012), Social Research Methods, Oxford: Open University Press.

Crawford, P., Lewis, L., Brown, B. and Manning, M. (2013), 'Creative practice as mutual recovery in mental health', Mental Health Review Journal, 18:2, pp. 55-64. 
Crawford, P., Brown, B., Baker, C., Tischler, V. and Abrams, B. (2015), Health Humanities, Palgrave Macmillan: Basingstoke.

Dorling, D. (2013), 'Fairness and the changing fortunes of people in Britain', Journal of the Royal Statistical Society: Series A (Statistics in Society), 176:1, pp. 97-128.

Elkis-Abuhoff, D., Goldblatt, R., Gaydos, M. and Corrato, S. (2008), 'Effects of clay manipulation on somatic dysfunction and emotional distress in patients with Parkinson's Disease', Journal of the American Art Therapy Association, 25:3, pp. $122-28$.

Goulding, A. (2014), 'Arts on prescription for older people: Different stakeholder perspectives on the challenges of providing evidence of impact on health outcomes', Journal of Applied Arts \& Health, 5:1, pp. 83-107.

Henley, D. (1991), 'Facilitating the development of object relations through the use of clay in Art Therapy', American Journal of Art Therapy, 29:3, pp. 69-80.

Henley, D. (2002), Clay Works in Art Therapy: Playing the Sacred Circle, London and USA: Jessica Kingsley Publishers.

Jung, C. (1995), Memories, Dreams, Reflections, London: Fontana Press.

Kameguchi, K. and Murphy-Shigematsu, S. (2001), 'Family psychology and family therapy in Japan', American Psychologist, 56:1, pp. 65-70.

NIMHANS, National Institute of Mental Health \& Neuro Sciences. (2007), Psycho-social Care for Children, Medium - Clay Modelling, India: Rukmini Printers.

Pernice-Duca, F. (2010), 'Family network support and mental health recovery', Journal of Marital and Family Therapy, 36:1, pp. 13-27.

Saavedra, J., Pérez, E., Crawford, P. and Arias, S. (2018), 'Recovery and creative practices in people with severe mental illness: evaluating well-being and social inclusion', Disability and Rehabilitation, 40:8, pp. 905-911.

Secker, J., Hacking, S., Kent, L., Shenton, J. and Spandler, H. (2009), 'Development of a measure of social inclusion for arts and mental health project participants', Journal of Mental Health, 18:1, pp. 65-72.

Sherwood, P. (2004), The Healing Art of Clay Therapy, Melbourne: ACER Press.

Sholt, M., Gavron, T. and Israel, H. (2006), 'Therapeutic qualities of clay work in art therapy: A review', Art Therapy: Journal of the American Art Therapy Association, 13:2, pp. 66-72.

Tennant, R., Hiller, L., Fishwick, R., Platt, S., Joseph, S., Weich, S., Parkinson, J., Secker, J. and Stewart-Brown, S. (2007), 'The Warwick-Edinburgh Mental Well-being Scale 
(WEMWBS): Development and UK validation', Health and Quality of Life Outcomes, 5:1, p. 63.

Van Lith, T., Schofield, M. and Fenner, P. (2013), 'Identifying the evidence-base for artbased practices and their potential benefit for mental health recovery: A critical review', Disability and Rehabilitation, 35:16, pp. 1309-1323.

Waller, D. (1993), 'Group Interactive Art Therapy', London: Routledge.

Walker, L. (2014), 'Recovery is for staff not just for people using services', Mental Health and Social Inclusion, 18:4, pp. 185-87.

White, P. (2006), 'Clay therapy, the Clinical Application of Clay with Children', in C.E. Schaefer and H. G. Kaduson (eds), Contemporary Play Therapy, New York: Guildford Press, pp. 270-92.

Winship, G. \& Haigh, R. (1998), 'The group matrix in clay: a contribution to group creative therapy'. Group Analysis, 31:1, pp. 71-81.

Winship, G. (2016), 'A meta-recovery framework: positioning the "New Recovery" movement and other recovery approaches', Journal of Psychiatric and Mental Health Nursing, 23:1, pp. 66-73.

\section{Contributor Details}

Dr Elaine Argyle is a dually registered mental health professional and has worked for many years in statutory and non-statutory welfare settings. After obtaining her $\mathrm{PhD}$ and completing an ESRC Postdoctoral Research Fellowship at the Department of Sociological Studies, University of Sheffield, she has worked on many projects relating to the arts and health including the mediums of theatre, music, museum resources, painting and drawing and ceramics. She was a Senior Research Fellow on the Clay Transformations project.

Contact: University of Nottingham, University Park, Nottingham NG7 2RD, UK E-mail: Elaine.Argyle@nottingham.ac.uk

Dr Gary Winship is a UKCP registered psychoanalytic psychotherapist and an NMC registered Mental Health Nurse. He is an Associate Professor in the School of Education, University of Nottingham and a Senior Fellow and arts co-ordinator at the Institute of Mental Health, Nottingham. He has extensive clinical and research experience in therapeutic environments, especially working with psychotic states, understanding the optimal conditions for an effective therapeutic milieu, including the resources of staff and team work. 
Contact: Room B16 Dearing, Jubilee Campus, Wollaton Road, Nottingham, NG8 1BB, UK E-mail: gary.winship@nottingham.ac.uk 